\title{
EXTREME GEOCHEMICAL VARIATION ACCOMPANYING DIAMOND GROWTH, GUANIAMO, VENEZUELA
}

\author{
Daniel J. Schulze ${ }^{1}$, Ben Harte ${ }^{2}$, John W. Valley ${ }^{3}$ and Dominic M.DeR. Channer ${ }^{4}$ \\ ${ }^{1}$ University of Toronto, Canada; ${ }^{2}$ University of Edinburgh, U.K.; ${ }^{3}$ University of Wisconsin, U.S.A.; \\ ${ }^{4}$ Guaniamo Mining Company, Venezuela
}

\section{INTRODUCTION}

Previous studies of diamonds and their mineral inclusions from the Guaniamo region of Venezuela have shown that the population is dominated by diamonds that belong to the eclogite-suite, and that most of the stones have unusually low carbon isotope ratios (Sobolev et al., 1998; Kaminsky et al., 2000). We have studied Guaniamo diamonds and their eclogite-suite mineral inclusions in situ in polished section by electron microprobe (EMP) analysis, cathodoluminescence (CL) and secondary ion mass spectrometry (SIMS), and have studied Guaniamo garnet xenocrysts by EMP and laser fluorination (LF).

\section{DIAMONDS}

Complex growth histories are inferred for most of the diamonds based on CL images (e.g., Figure 1) and the fact that, in some diamonds, compositions of multiple inclusions of the same mineral vary within single stones. All diamonds analysed by SIMS are zoned in carbon isotope ratio, with higher $\delta^{13} \mathrm{C}_{\mathrm{PDB}}$ in rims than in cores. The most dramatic zoning recognized to date occurs in diamond $\# 27$, which has six garnet inclusions, three of which are exposed in the half of the stone illustrated in Figure 1. The bulk of this stone is characterised by dark and rather featureless CL response, whereas the rim $\mathrm{CL}$ is brighter and more complex. Garnet 1 occurs in the dark (early) region and garnets 2 and 3 occur in a re-entrant into the stone that is connected to the rim and has the same rim CL characteristics. The carbon isotope ratios $\left(\delta^{13} \mathrm{C}\right)$ of the early portion of the stone are in range -15.9 to $-20.0 \%$ and those of the late diamond filling the re-entrant in the range -9.3 to $-6.2 \%$ (Figure 1). (Some analytical volumes sampled both zones and have intermediate $\delta^{13} \mathrm{C}$ values). Garnet 1 in the dark core region is more $\mathrm{Fe}$ - and Ca-rich $(\mathrm{Mg} /(\mathrm{Mg}+\mathrm{Fe})=0.56, \mathrm{Ca} /(\mathrm{Ca}+\mathrm{Mg})=$ 0.27 ) than garnets 2 and 3 (which are identical to each other) in the late-formed re-entrant $(\mathrm{Mg} /(\mathrm{Mg}+\mathrm{Fe})=$ $0.61, \mathrm{Ca} /(\mathrm{Ca}+\mathrm{Mg})=0.22)$. This compositional trend in a single diamond is within, and parallel to, that published for the population of garnet inclusions in
Guaniamo diamonds (Sobolev et al., 1998; Kaminsky et al., 2000).

The oxygen isotope compositions (SIMS) of three coesite inclusions in two diamonds $\left(\delta^{18} \mathrm{O}_{\text {VSMOW }}=+10.1\right.$ to $+16.7 \%$ ) and eight garnet inclusions in four diamonds $\left(\delta^{18} \mathrm{O}_{\text {VSMOW }}=+7.9\right.$ to $\left.+12.9 \%\right)$ range to values considerably higher than previously recorded in mantle materials. A solitary garnet in one diamond has a "normal" mantle oxygen isotope ratio $\left(\delta^{18} \mathrm{O}_{\mathrm{VSMOW}}=\right.$ $+5.5 \%$ ). Garnets 1,2 and 3 in diamond \#27 have oxygen isotope ratios of $+10.5,+8.3$ and $+7.9 \%$, respectively, which are very similar to each other, considering analytical errors.

\section{XENOCRYSTS}

$\delta^{18} \mathrm{O}$ values (LF) of 14 Guaniamo eclogite garnet xenocrysts range from normal to moderately high values relative to typical mantle $(+5.32$ to $+9.26 \%)$, significantly lower than most of the diamond inclusion minerals. The eclogitic garnet xenocrysts and the diamond inclusion garnets overlap in major and minor element composition, and each group shows a positive correlation between $\mathrm{Mg} /(\mathrm{Mg}+\mathrm{Fe})$ and $\mathrm{Cr}$ content. The xenocryst population extends to more $\mathrm{Mg}$ - and Cr-rich compositions than does the diamond inclusion garnet suite.

\section{DISCUSSION}

Many workers interpret eclogite oxygen isotope values that are above those of typical upper mantle as indicating that the precursors of the eclogites were ocean floor basalts that experienced low-temperature alteration on or near the sea floor and were later subducted (e.g., Jagoutz et al., 1984). Furthermore, anomalously low $\delta^{13} \mathrm{C}$ values of eclogite-suite diamonds are commonly interpreted as indicating a component of subducted biogenic carbon (e.g., Kirkley et al., 1991). Other workers, however, maintain that low $\delta^{13} \mathrm{C}$ values in eclogitic diamond are the results of mantle fractionation processes (e.g., Cartigny et al., 1999). Our documentation of low $\delta^{13} \mathrm{C}$ diamonds coexisting with silicate inclusions with extremely 

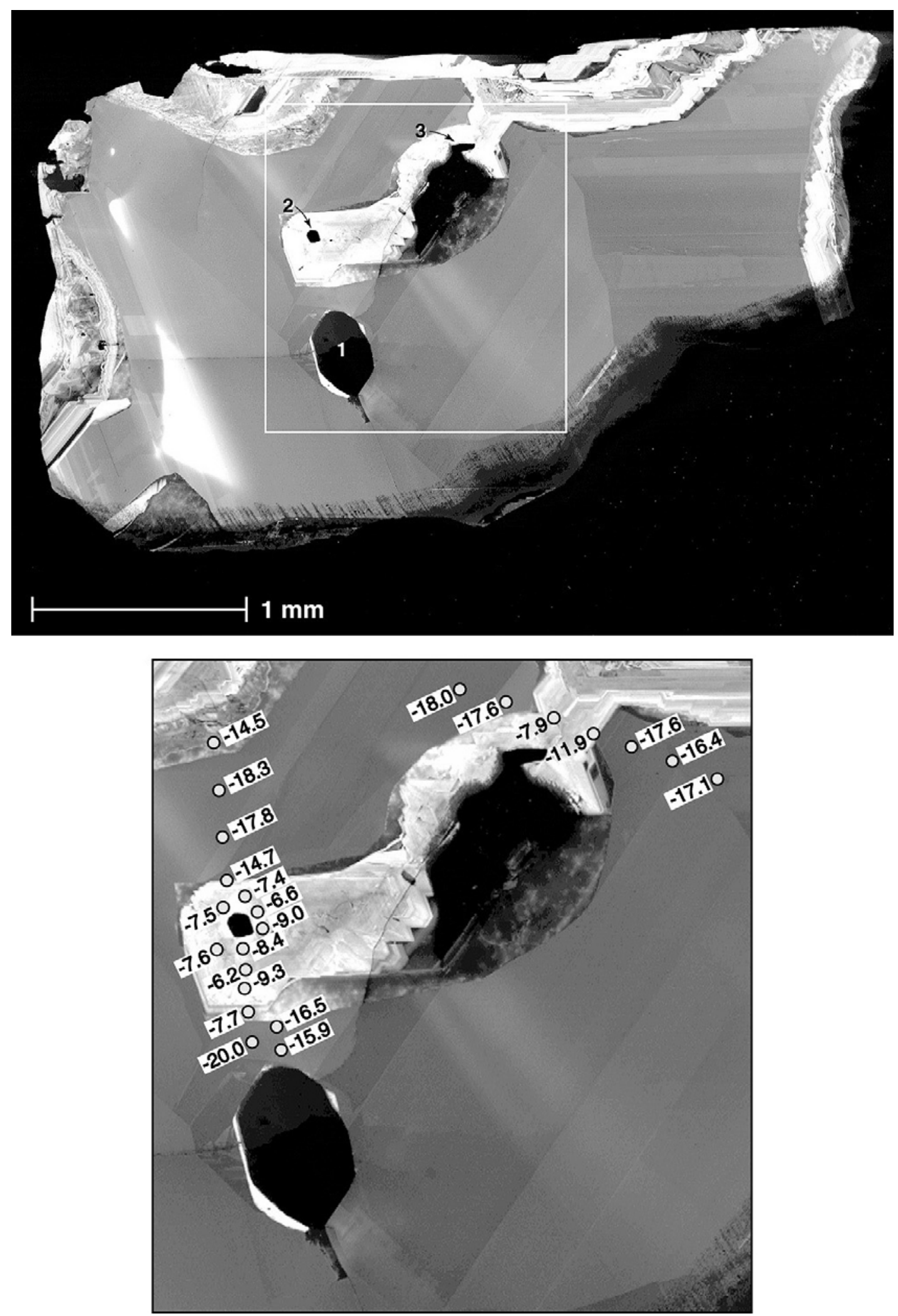

Figure 1. CL image of diamond \#27. The entire stone is shown in the upper image, and garnets 1,2 and 3 indicated within the highlighted area. An expanded view of this area is shown in the lower image, with carbon isotope values for points analysed by SIMS. 
elevated $\delta^{18} \mathrm{O}$ values (almost certainly a crustal signature) gives very strong support to a biogenic source for the low $\delta^{13} \mathrm{C}$ of the diamonds.

We suggest that the eclogitic diamonds from Guaniamo formed in an evolving geochemical system during or following subduction of an oceanic basalt protolith having a strong imprint of low-temperature hydrothermal alteration or sea floor weathering, and a significant biogenic component in its carbon budget. The changes in garnet composition indicate that as the silicate component of the system evolved away from $\mathrm{Fe}$ - and Ca-rich compositions, the carbon isotope composition of the armouring diamonds changed from biogenic-like subducted carbon to heavier carbon more like the typical upper mantle. The garnet evolutionary trend of increasing $\mathrm{Mg}$ and $\mathrm{Cr}$ contents demonstrates that this was not a fractionating igneous system, but one in which the anomalous crustal component was increasingly contaminated by exchange with (or at least input from) the host mantle. The oxygen isotope data demonstrate that the extreme crustal $\delta^{18} \mathrm{O}$ values survived subduction at least to the point of diamond formation, but were later smoothed to varying extents in the unarmoured portions of the eclogite host by diffusive relaxation and oxygen isotope exchange with the surrounding mantle.

\section{REFERENCES}

Cartigny, P., Harris, J.W., Javoy, M., 1999. Eclogitic, peridotitic and metamorphic diamonds and the problems of carbon recycling - The case of Orapa (Botswana). In: Gurney, J.J., Gurney, J.L., Pascoe, M.D., Richardson, S.H. (Eds.), Proceedings of the VIIth International Kimberlite Conference, Vol. 1. Red Roof Design, Cape Town, pp. 117-124.

Jagoutz, E., Dawson, J.B., Hoernes, S., Spettel, B., Wanke, H., 1984. Anorthositic oceanic crust in the Archean. Lunar Planet. Sci. 15, 395-396.

Kaminsky, F.V., Zakharchenko, O.D., Griffin, W.L., Channer, D.M.deR., Khachatrayan-Blinova, G.K., 2000. Diamond from the Guaniamo area, Venezuela. Can. Mineral. 38, 1347-1370.

Kirkley, M.B., Gurney, J.J., Otter, M.L., Hill, S.J., Daniels, L.R., 1991. The application of C isotope measurements to the identification of the sources of $\mathrm{C}$ in diamonds: a review. Appl. Geochem. 6, 447-494.

Sobolev, N.V., Efimova, E.S., Channer, D.M.deR., Anderson, P.F.N., Barron, K.M., 1999. Unusual upper mantle beneath Guaniamo, Guyana Shield, Venezuela: evidence from diamond inclusions. Geology 26, 971974.
Contact: D. Schulze, Dept. of Geology, University of Toronto, Erindale College, 3359 Mississauga Rd. N., Mississauga, ON, Canada, L5L 1C6, E-mail:

dschulze@utm.utoronto.ca 